f. med. Genet. (1969). 6, 399.

\title{
Anomalies of Chromosome No. 3 in Abortuses*
}

\author{
DAVID T. ARAKAKI, SORRELL H. WAXMAN, and TULINE M. NONOMURA \\ From the Department of Genetics, School of Medicine, University of Hawaii
}

Cytogenetic studies have shown that chromosomal abnormalities are a significant factor in many spontaneous abortions, having been found in nearly 20 $40 \%$ of specimens successfully cultured (Geneva

Received March 14, 1969.

* Requests for reprints should be sent to Cytogenetics Laboratory, Kapiolani Maternity Hospital, Honolulu, Hawaii.
Conference, 1966; Waxman, Arakaki, and Smith, 1967). In the Geneva study of more than $150 \mathrm{ab}-$ normal karyotypes, only 12 mosaics and 3 translocations were reported. We report here a case of a $46, \mathrm{XY} / 46, \mathrm{XY}, 3 \mathrm{r}$ mosaicism in a spontaneous abortion and summarize the results of other reported cases of chromosome No. 3 anomalies found in foetal abortions.

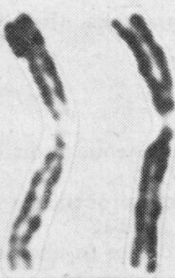

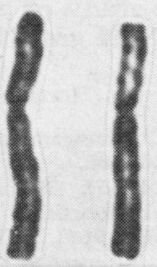

2

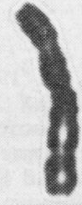

3

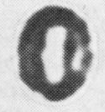

$3 r$

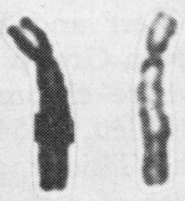

$4-5$
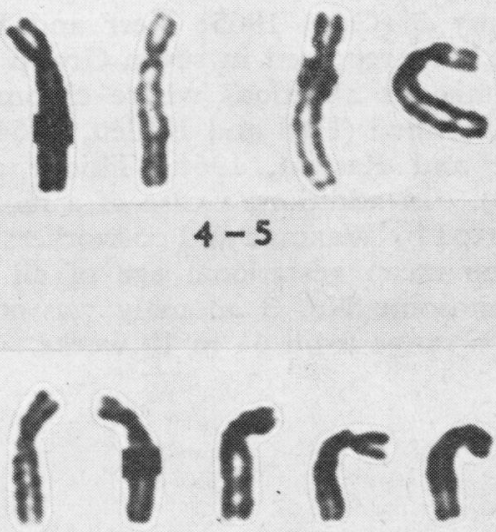

$6-12+x$
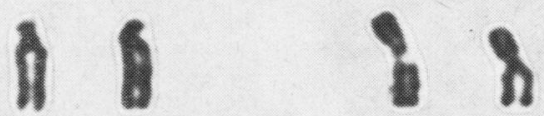

है
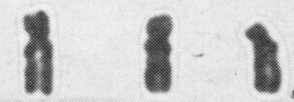

$16-18$

$\times 8$

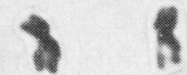

$19-20$

FIG. The ring-3 chromosome complement. 


\section{Case Report}

The expelled products of this conception contained only an empty amniotic sac. No actual embryonic tissue was present. The maternal age was 33 years and the gestational age was $6 \frac{1}{2}$ weeks (total lapsed days from last menstrual period to abortion minus 14 days). The mother had intermittent bleeding since her last normal menstrual period. She was being treated concurrently with progesterone for the vaginal bleeding and with antibiotics, cortisone, and expectorants for chronic bronchitis. No information was available concerning exposure to $x$-rays before or after conception.

Cytogenetic observations. Twenty-seven fibroblast cells grown from the chorionic base had a chromosome number of 46 . In 7 cells or $23 \%$, a missing chromosome No. 3 was replaced by a large monocentric ring chromosome (Fig.). The conceptus was a mosaic $46, X Y / 46, X Y, 3 r$.

\section{Comments}

The present report is the first case of a ring chromosome found in a spontaneous abortion and the fourth spontaneous abortion case involving an anomaly of chromosome No. 3. Two cases of trisomy 3 (Carr, 1965; Kerr and Rashad, 1966) have been reported in seven Group A trisomies in spontaneous abortions where chromosomes could be identified (Hall and Källén, 1964; Carr, 1965; Kerr and Rashad, 1966; Thiede and Metcalfe, 1966). In addition, a case of a monosomy-3 was reported by Waxman and co-workers (1967).

The mean gestational age of all four cases of chromosome No. 3 anomaly was only $7 \cdot 9$ weeks, with a range from $6 \frac{1}{2}$ to 10 weeks. This is much lower than the gestational ages reported by Carr (1965) for chromosomally normal and chromosomally abnormal abortuses, 13.2 weeks and 10.3 weeks, respectively, and may indicate that anomalies of chromosome No. 3 are lethal very early in embryonic life. The mean maternal age of the four cases was 29.7 years with a range from 25 to 36 years. This does not differ from the mean age reported by Carr (1965) of $28.9( \pm 1 \cdot 19)$ years for all chromosomally abnormal specimens, but is higher than the $27 \cdot 1$ years reported for all normal abortuses. The sex ratio was $1: 1$.

\section{Summary}

A ring chromosome No. 3 was found in an early spontaneous abortion. The clinical data of two additional trisomy-3 and a monosomy-3 were reviewed. Abnormalities of chromosome No. 3 are apparently lethal in very early embryonic development.

The cytogenetic study of early spontaneous abortion was supported by NIH grant HD-01133.

\section{REFERENCES}

Carr, D. H. (1965). Chromosome studies in spontaneous abortions. Obstet. and Gynec., 26, 308.

Geneva Conference (1966). Standardization of procedures for chromosome studies in abortion. Cytogenetics, $\mathbf{5}, 361$.

Hall, B., and Källén, B. (1964). Chromosome studies in abortuses and stillborn infants. Lancet, 1, 110.

Kerr, M., and Rashad, M. N. (1966). Chromosome studies on? spontaneous abortions. Amer. F. Obstet. Gynec., 94, 322.

Thiede, H. A., and Metcalfe, S. (1966). Chromosomes and human pregnancy wastage. ibid., 96, 1132.

Waxman, S. H. Arakaki, D. T., and Smith, J. B. (1967). Cytogenetics of fetal abortions. Pediatrics, 39, 425. 